\title{
Soft-tissue sarcomas in the head and neck: 25 years of experience
}

\author{
Juan Francisco Liuzzi ${ }^{1}$, Maribel Da Cunha², Daniuska Salas², Saul Siso² and Esteban Garriga² \\ ${ }^{1}$ Head and Neck Department, Hospital Oncology Service, Venezuelan Institute of Social Security, Caracas 1040, Venezuela \\ ${ }^{2} \mathrm{Head}$ and Neck Cancer Surgery, Hospital Oncology Service, Venezuelan Institute of Social Security, Caracas 1040, Venezuela \\ Correspondence to: Da Cunha. Email: jfliuzzi@gmail.com
}

\section{Abstract}

Sarcomas are infrequent and heterogeneous tumours. They represent $1-2 \%$ of all malignant neoplasms in adults and between $4 \%$ and $10 \%$ of head and neck cancers.

Methods: The research was retrospective, descriptive, and cross-sectional.

Results: A study population of 62 patients with a mean age of 44 years was obtained; the most frequent location was the soft tissues of the neck $(25.3 \%)$ and the mean tumour size was $7.1 \mathrm{~cm}$; the most frequent diagnosis was undifferentiated pleomorphic sarcoma (25.5\%) and the majority were stage III (41.4\%). The lowest survival rates were associated with T2a and T2b tumours $(p=0.014)$, the presence of lymph node metastasis $(p=0.001)$, advanced stages $(p=0.003)$, and invasion of bone, blood vessels and/or nerves $(p=0.008)$.

Conclusions: Late diagnosis is the main factor associated with decreased survival in patients with head and neck sarcomas.

Keywords: soft-tissue sarcoma, head and neck neoplasms, head, neck

ecancer 2017, 11:740 https://doi.org/10.3332/ecancer.2017.740

Copyright: (c) the authors; licensee ecancermedicalscience. This is an Open Access article distributed under the terms of the Creative Commons Attribution License (http://creativecommons.org/licenses/by/3.0), which permits unrestricted use, distribution, and reproduction in any medium, provided the original work is properly cited. 


\section{Introduction}

Sarcomas are infrequent and heterogeneous tumours. They represent $1-2 \%$ of all adult malignant neoplasms and between $4 \%$ and $10 \%$ of head and neck cancers [1-4]. More than 50 histological varieties have been described with different biological behaviours [5]. The natural history of head and neck sarcomas is similar to that of sarcomas of the limbs; however, the anatomical complexity of this area makes surgical management difficult, since extensive surgery, with significant functional and aesthetic sequelae, is required to obtain adequate margins. Factors such as the histological subtype, degree of differentiation, and extent of the disease influence the patient's survival and should be taken into consideration when preparing the treatment plan [5].

The purpose of this research was to evaluate the clinical characteristics and factors influencing the survival of patients with soft-tissue sarcomas in the Social Security Institute's Hospital Oncology Service (SOH-IVSS) in the period between 1991 and 2016.

\section{Materials and methods}

Sixty-two patients with soft-tissue sarcomas of the head and neck were treated in the SOH-IVSS between 1991 and 2016 . Patients with bone sarcomas, carcinosarcomas, and Kaposi's sarcoma, as well as patients of paediatric age, were excluded from the study.

Sarcomas were classified histologically according to the definitions set forth by the World Health Organisation (WHO), and the American Joint Committee on Cancer (AJCC) 7th edition (2010) classification was used to determine the stage of the patients' tumours [7]. The tumour differentiation grade was established using the French FNCLCC (Fédération Nationale de Centres de Lutte Contre le Cancer [National Federation of Cancer Research Centers]) gradation system [8]. A R0 resection was considered when the margins were negative, $R 1$ when they were microscopically positive, and $R 2$ in the case of macroscopic residual disease.

The research was retrospective, descriptive, and cross sectional. The following variables were evaluated: age, sex, location, symptoms, histological subtype, tumour size, differentiation grade, the presence of nodal disease and remote metastasis, treatment performed and surgical margins.

The mean and standard deviation of the continuous variables were calculated, as well as the frequency and percentages of the nominal variables. Overall survival (OS) was analysed for the different evaluated factors. The calculation of overall survival was based on KaplanMeier's non-parametric model. Survival curves were compared with the log-rank procedure and were considered to be statistically significant if $p<0.05$. The multivariable analysis was performed using Cox regression.

\section{Results}

The mean age of patients with soft-tissue sarcomas of the head and neck was 45 years with a standard deviation of 19 years; the time from onset of disease to the first evaluation in our hospital was 6 months: (interval 1-360); the mean tumour size was $7.1 \mathrm{~cm}$ with a standard deviation of $4.0 \mathrm{~cm}$. There were more males than females (54.8\% vs. $45.2 \%)$. The most frequent symptom was the presence of a tumour in $92 \%$; other symptoms were dysphonia (4.8\%) and nasal obstruction and/or epistaxis (3.2\%). Regarding location, $25.9 \%$ originated in the soft tissue of the neck; $22.6 \%$ in the maxillary antrum; $14.5 \%$ in the oral cavity; $14.5 \%$ on the scalp; $12.9 \%$ on facial skin, among others (Table 1 ).

Based on the Tumour, Node, Metastasis (TNM) categorisation of tumours according to the AJCC classification, $49.9 \%$ were classified as T2b tumours, corresponding to tumours larger than $5 \mathrm{~cm}$ located in a deep plane. With respect to lymph node status, the most frequent category was N0 in $96.8 \%$ of cases. There was an absence of remote metastasis at the time of diagnosis in $95.2 \%$ of cases.

Regarding the clinical stage, the majority were stage III (40.2\%); followed by stage la and Ib, with 19.4\% each (Table 2).

Regarding the nuclear grade, most tumours were considered to be poorly differentiated (grade 3) at 61.3\%; well-differentiated tumours (grade 1) occurred in $30.6 \%$ of cases and moderately differentiated tumours (grade 2 ) in $7.9 \%$ (Table 2). Undifferentiated pleomorphic sarcoma was the most frequently observed histological type (24.2\%), followed by malignant peripheral nerve sheath tumours (Table 3 ). 
Table 1. Characteristics of the sample according to clinical and epidemiological indicators.

\begin{tabular}{|c|c|}
\hline Variables & Statistics \\
\hline Number of patients & 62 \\
\hline Age (years) $\left(^{*}\right)$ & $45 \pm 19$ \\
\hline Evolution time (months) $\left(^{* *}\right)$ & $6(1-360)$ \\
\hline Size $(\mathrm{cm})\left(^{*}\right)$ & $7.1 \pm 4.0$ \\
\hline \multicolumn{2}{|l|}{ Sex } \\
\hline Male & $34(54.8 \%)$ \\
\hline Female & $28(45.2 \%)$ \\
\hline \multicolumn{2}{|l|}{ Symptoms } \\
\hline Tumour & $57(92.0 \%)$ \\
\hline Dysphonia & $3(4.8 \%)$ \\
\hline Nasal obstruction and/or epistaxis & $2(3.2 \%)$ \\
\hline \multicolumn{2}{|l|}{ Location } \\
\hline Soft tissue of the neck & $16(25.9 \%)$ \\
\hline Maxillary antrum and/or nasal fossa & $14(22.6 \%)$ \\
\hline Oral cavity & $9(14.5 \%)$ \\
\hline Scalp & $9(14.5 \%)$ \\
\hline Facial skin & $8(12.9 \%)$ \\
\hline Larynx & $3(4.8 \%)$ \\
\hline Oropharynx & $1(1.6 \%)$ \\
\hline Ethmoidal or sphenoidal sinus & $1(1.6 \%)$ \\
\hline Parotid & $1(1.6 \%)$ \\
\hline
\end{tabular}

$\left({ }^{*}\right)$ mean \pm deviation

$\left({ }^{* *}\right)$ median (minimum-maximum)

Regarding the involvement of the tumour in neighbouring structures (Table 4), in $62.9 \%$ of cases, there was no evidence of involvement of the bone or neurovascular structures, whereas $30.6 \%$ had bone involvement and $6.5 \%$ involvement of blood vessels and/or nerves.

Regarding the treatment received, $43.5 \%$ were treated with surgery alone; $35.5 \%$ with surgery followed by external beam radiation therapy, and $14.3 \%$ were not able to be treated surgically. Of the patients operated on, the majority $(69.8 \%)$ had wide and negative resection margins, $30.2 \%$ had microscopically positive margins and none had macroscopically positive margins.

Until the end of follow-up, $51.5 \%$ did not present with relapses, while $37.2 \%$ had some type of relapse during their treatment. It was also observed that $11.3 \%$ progressed under treatment.

Table 5 presents the final indicators; the disease-free interval (DFI) had a median of 19 months (mean 43 months); the follow-up had a median of 20 months (mean 44 months). At the end of the follow-up, 50\% of the patients were alive without disease and $35.5 \%$ dead with disease. Age, tumour size, and the presence of negative margins were not associated with survival. T2a and T2b tumours $(p=0.014)$, the presence of lymph node metastasis $(p=0.001)$, advanced stages $(p=0.003)$, and invasion of bone, blood vessels and/or nerves $(p=0.008)$ are associated with decreased survival (Figures $1-4)$.

T2a and T2b tumours $(p=0.002)$, stages III and IV $(p=0.019)$ and the involvement of blood vessels, nerves and/or bone were associated with decreased survival in the multivariable analysis (Table 6). 
Table 2. Characteristics of the sample according to anatomopathological indicators.

\begin{tabular}{|c|c|}
\hline Variables & NP $\%$ \\
\hline \multicolumn{2}{|l|}{ T classification } \\
\hline T1a & $6 \quad(9.7)$ \\
\hline $\mathrm{T} 1 \mathrm{~b}$ & $12(19.4)$ \\
\hline T2a & $13(21.0)$ \\
\hline $\mathrm{T} 2 \mathrm{~b}$ & 31 (49.9) \\
\hline \multicolumn{2}{|l|}{$\mathrm{N}$ classification } \\
\hline No & $60(96.8)$ \\
\hline N1 & $2(3.2)$ \\
\hline \multicolumn{2}{|l|}{ M classification } \\
\hline M0 & $59(95.2)$ \\
\hline M1 & $3(4.8)$ \\
\hline \multicolumn{2}{|l|}{ Nuclear grade } \\
\hline Grade 1 & $19(30.6)$ \\
\hline Grade 2 & $5(8.1)$ \\
\hline Grade 3 & 38 (61.3) \\
\hline \multicolumn{2}{|l|}{ Stage } \\
\hline la & $6(9.7)$ \\
\hline $\mathrm{lb}$ & $12(19.4)$ \\
\hline Ila & $12(19.4)$ \\
\hline $\mathrm{Ilb}$ & $4(6.5)$ \\
\hline III & $25(40.2)$ \\
\hline IV & $3(4.8)$ \\
\hline
\end{tabular}

$\mathrm{NP}=$ number of patients

Table 3. Characteristics of the sample according to the histological diagnosis.

\begin{tabular}{|l|c|}
\hline \multicolumn{1}{|c|}{ Histological diagnosis } & NP \% \\
\hline Undifferentiated pleomorphic sarcoma & $15(24.2)$ \\
\hline Fibrosarcoma & $10(16.1)$ \\
\hline Leiomyosarcoma & $9(14.5)$ \\
\hline Dermatofibrosarcoma & $6(9.7)$ \\
\hline Malignant peripheral nerve sheath tumour & $5(8.0)$ \\
\hline Pleomorphic rhabdomyosarcoma & $4(6.5)$ \\
\hline Angiosarcoma & $4(6.5)$ \\
\hline Liposarcoma & $4(6.5)$ \\
\hline Synovial sarcoma & $2(3.2)$ \\
\hline Lone fibrous tumour & $2(3.2)$ \\
\hline Myxofibrosarcoma & $1(1.6)$ \\
\hline
\end{tabular}

$\mathrm{NP}=$ number of patients 
Table 4. Characteristics of the sample according to clinical-surgical indicators.

\begin{tabular}{|c|c|}
\hline Variables & NP $\%$ \\
\hline \multicolumn{2}{|l|}{ Involvement } \\
\hline No involvement & $39(62.9)$ \\
\hline Bone & $19(30.6)$ \\
\hline Blood vessels and/or nerves & $4(6.5)$ \\
\hline \multicolumn{2}{|l|}{ Treatments } \\
\hline Just surgery & $27(43.5)$ \\
\hline Surgery + POEBRT* & $22(35.5)$ \\
\hline Surgery + POEBRT + $\mathrm{CT}^{* *}$ & $4(6.5)$ \\
\hline Just CT & $1(1.6)$ \\
\hline Just EBRT*** & $2(3.2)$ \\
\hline $\mathrm{CT}+\mathrm{EBRT}$ & $6(9.7)$ \\
\hline \multicolumn{2}{|l|}{ Margins } \\
\hline$R 0$ & $37(69.8)$ \\
\hline$R 1$ & $16(30.2)$ \\
\hline$R 2$ & 0 \\
\hline \multicolumn{2}{|l|}{ Relapse } \\
\hline No relapse & $32(51.5)$ \\
\hline Local relapse & $12(19.4)$ \\
\hline Remote relapse & $6(9.7)$ \\
\hline Local and remote relapse & $5(8.1)$ \\
\hline Progression and/or persistence under treatment & $7(11.3)$ \\
\hline
\end{tabular}

$\mathrm{NP}=$ number of patients

${ }^{*}$ Postoperative external beam radiation therapy.

${ }^{* *}$ Chemotherapy.

${ }^{* * *}$ External beam radiation therapy.

Table 5. Characteristics of the sample according to final events.

\begin{tabular}{|l|c|}
\hline \multicolumn{1}{|c|}{ Variables } & Statistics \\
\hline Disease-free interval (months) $\left(^{* / *}\right)$ & $19 / 43(1-211)$ \\
\hline Follow-up (months) $\left(^{* / * *}\right)$ & $20 / 44(1-211)$ \\
\hline Final results & \\
\hline Alive without disease & $31(50.0 \%)$ \\
\hline Alive with disease & $3(4.8 \%)$ \\
\hline Dead with disease & $22(35.5 \%)$ \\
\hline Dead without disease & $5(8.1 \%)$ \\
\hline Losses & $1(1.6)$ \\
\hline
\end{tabular}

$\left.{ }^{(* *}\right)$ median $\left({ }^{*}\right)$ mean (minimum-maximum) 


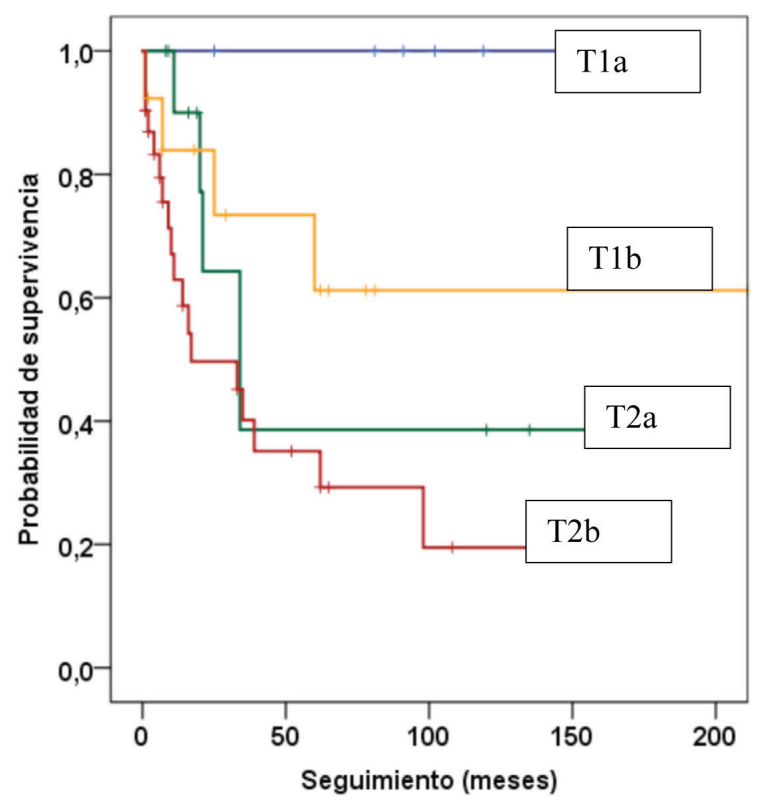

Log-rank: $p=0.014$

\begin{tabular}{|l|c|c|c|}
\hline T classification & Median & \multicolumn{2}{|c|}{$95 \%$ Cl } \\
\hline T1a & 97 & 25 & 149 \\
\hline T1b & 21 & 8 & 183 \\
\hline T2a & 29 & 1 & 211 \\
\hline T2b & 11 & 1 & 139 \\
\hline
\end{tabular}

Figure 1. Kaplan-Meier survival curve according to T classification.

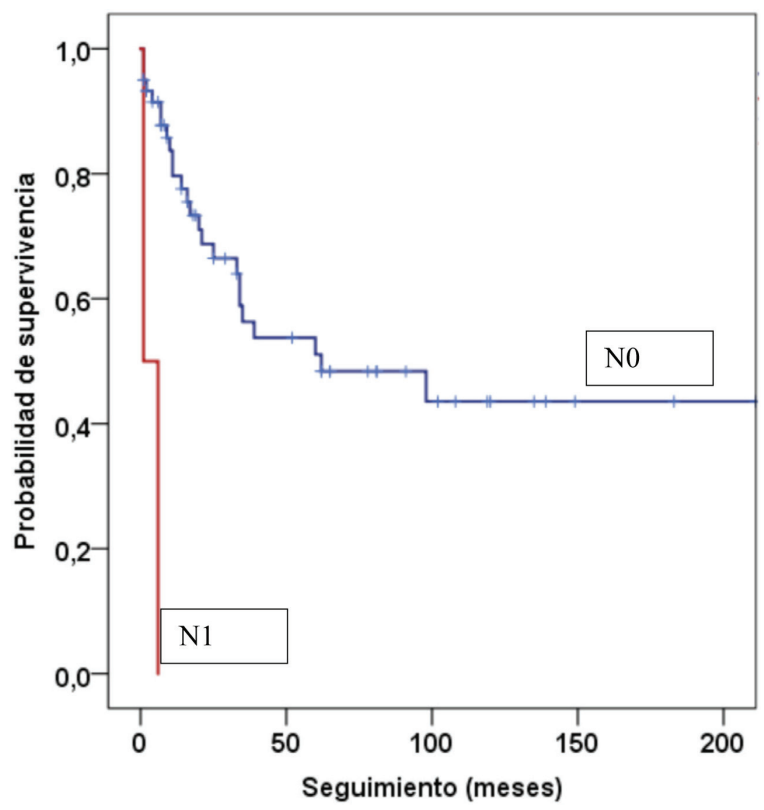

Log-rank: $p=0.001$

\begin{tabular}{|l|c|c|c|}
\hline N classification & Median & \multicolumn{2}{|c|}{$95 \%$ Cl } \\
\hline N0 & 60 & 1 & 211 \\
\hline N1 & 4 & 1 & 21 \\
\hline
\end{tabular}

Figure 2. Kaplan-Meier survival curve according to $\mathbf{N}$ classification. 


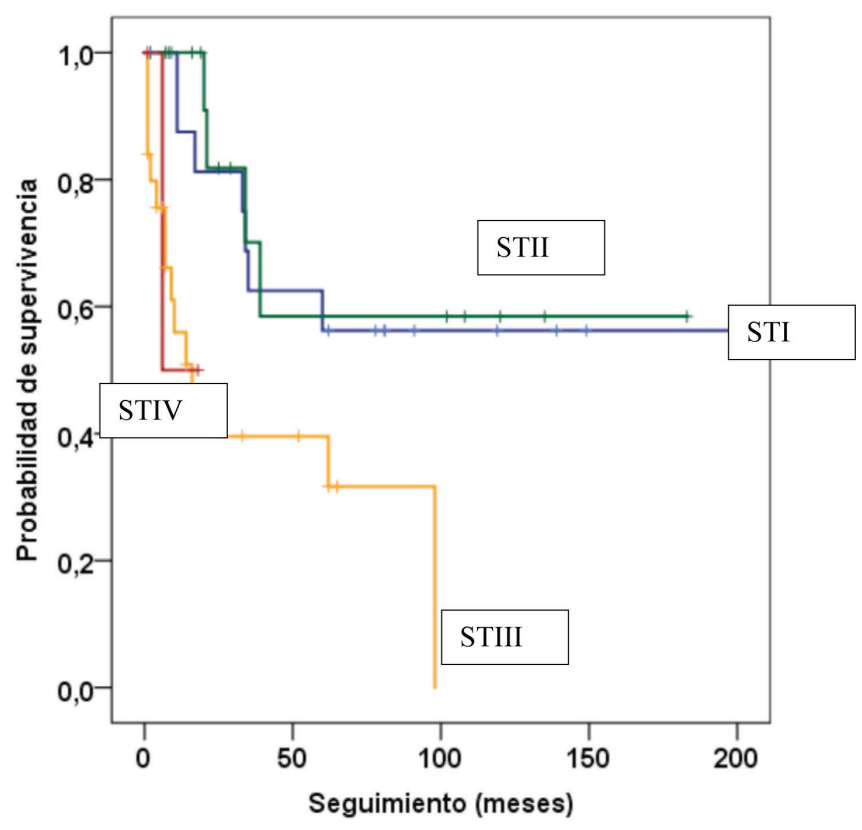

Log-rank: $p=0.003$

\begin{tabular}{|l|c|c|c|}
\hline Stages & Median & \multicolumn{2}{|c|}{$95 \% \mathbf{C I}$} \\
\hline I & 60 & 2 & 211 \\
\hline II & 25 & 1 & 183 \\
\hline III & 9 & 1 & 98 \\
\hline IV & 12 & 1 & 23 \\
\hline
\end{tabular}

Figure 3. Kaplan-Meier survival curve according to stage.

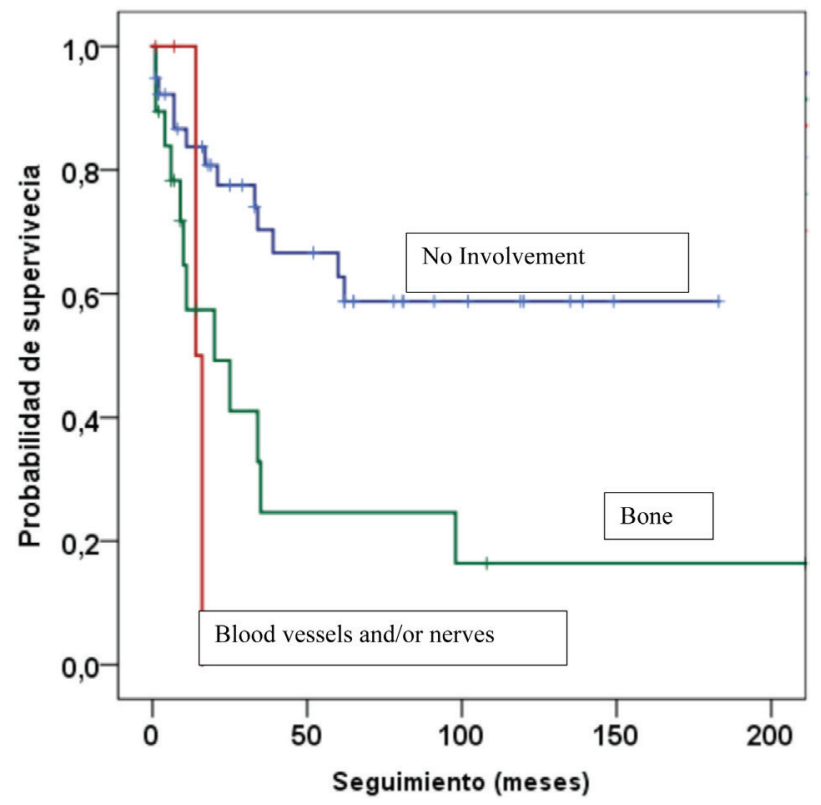

Log-rank: $p=0.008$

\begin{tabular}{|l|c|c|c|}
\hline \multicolumn{1}{|c|}{ Involvement } & Median & \multicolumn{2}{c|}{$95 \%$ Cl } \\
\hline No involvement & 34 & 1 & 183 \\
\hline Bone & 10 & 1 & 211 \\
\hline Blood vessels and/or nerves & 11 & 1 & 23 \\
\hline
\end{tabular}

Figure 4. Kaplan-Meier survival curve according to involvement. 
Table 6. Cox regression.

\begin{tabular}{|l|c|c|c|c|}
\hline \multicolumn{1}{|c|}{ Variables } & RR & \multicolumn{2}{c|}{$\mathbf{9 5 \%}$ CI } & $\mathbf{p}$ \\
\hline Age ( > 45 years) & 1.09 & 0,37 & 3.25 & 0.265 \\
\hline T classification (T2a or T2b) & $\mathbf{5 . 1 9}$ & $\mathbf{1 . 5 7}$ & $\mathbf{1 7 . 1 6}$ & $\mathbf{0 . 0 0 2}$ \\
\hline N classification (N1) & 1.30 & 0.99 & 2.16 & 0.547 \\
\hline M classification (M1) & 1.02 & 0.90 & 2.09 & 0.485 \\
\hline Nuclear grade (G3) & 0.55 & 0.14 & 1.12 & 0.591 \\
\hline Stage (III or IV) & $\mathbf{3 . 6 4}$ & $\mathbf{1 . 1 3}$ & $\mathbf{5 . 1 4}$ & $\mathbf{0 . 0 1 9}$ \\
\hline Involvement (yes) & $\mathbf{2 . 7 1}$ & $\mathbf{1 . 0 6}$ & $\mathbf{6 . 9 2}$ & $\mathbf{0 . 0 3 7}$ \\
\hline Margins (positive) & 2.35 & 0.72 & 7.68 & 0.159 \\
\hline
\end{tabular}

\section{Discussion}

Head and neck sarcomas are infrequent and heterogeneous tumours. Studies of this entity are limited by the small number of patients and the different biological behaviour of the distinct histological subtypes [9].

In this research, the mean age was 45 years, the male sex was the most frequently affected (54.8\%) and the mean tumour size was $7.1 \mathrm{~cm}$. In general, the age of presentation is between 50 and 60 years when the paediatric population is not included [2, 9, 10]. The younger mean age of diagnosis in our study cannot be explained by early diagnosis as $70.9 \%$ of the patients had tumours larger than $5 \mathrm{~cm}$.

As in most of the reports, predominance of the male sex was observed [5, 9-11]. The data on the stage of the disease at the time of diagnosis are varied, Barker et al. had only $11 \%$ of head and neck sarcomas diagnosed in stages III and IV [10]; in our research, $45 \%$ presented in these stages.

Differences in the way of grouping the areas where the sarcomas originate makes it difficult to compare the series. Salcedo et al. report in their research that the two most frequent locations were the paranasal sinuses and the soft tissues of the neck, as in our study [9]. Because of their proximity to vital structures, head and neck sarcomas present surgical difficulties and, depending on their location, may be managed with greater or lesser difficulty. Tumours located in the soft tissues of the neck or on the scalp tend to be more easily treated, but tumours located in the paranasal sinuses tend to be in the vicinity of the brain, which makes treatment more complex; this translates into a greater likelihood of positive margins after surgery.

A relevant factor in the classification of sarcomas is their histological grade; in our research, this was not associated with a decrease in survival, however, this link has been established in other research [5, 9-11].

Whenever feasible, surgery is the central element in the treatment of soft-tissue sarcomas. In our series, as in most reports, surgical treatment was performed on the majority of patients. Given the anatomical complexity of the head and neck area, obtaining negative margins is not always possible. In our research, $30.2 \%$ of the cases had microscopically positive margins; this coincides with the data reported by Salcedo et al.; however, in our case, this factor had no adverse effects on survival [9].

Invasion of adjacent structures is an infrequent phenomenon in head and neck sarcomas. According to Le Vay et al., an independent prognostic factor which is considered to be highly significant in terms of local control and survival is tumoural involvement of the bone, neurovascular structures or the skin [12]. In our study, invasion of adjacent structures was an important factor, occurring in $37.1 \%$ of cases. Invasion of neighbouring structures was a significant factor for decreased survival.

As in most series, advanced stages (III and IV), the presence of lymph node metastasis, tumour size greater than $5 \mathrm{~cm}$ and invasion of bone, blood vessels, and/or nerves adversely and significantly affected the survival of the patients [5, 9-14]. 


\section{Conclusions}

Soft-tissue sarcomas of the head and neck are heterogeneous tumours with different biological behaviour depending on their histological type and degree of differentiation. Our research evaluated 62 patients with a diagnosis of soft-tissue sarcoma of the head and neck treated over a 25-year period. Several factors were discovered, which are considered to be prognoses of survival. One of these was tumour size; tumours larger than $5 \mathrm{~cm}$ usually had a worse prognosis than those measuring less than $5 \mathrm{~cm}$. Another prognostic factor was the stage; patients with stage III and IV tumours had lower survival than those with earlier stage tumours. Finally, the invasion of neighbouring structures, such as bone, nerves, and/or blood vessels, which is directly correlated with increased local aggressiveness of the tumour, also represented a significant prognostic factor.

Major prognostic factors should be taken into account to determine which lesions should be considered to be potentially recurrent and to choose the most effective treatment regime.

The management of these tumours continues to be a major challenge for the multidisciplinary cancer team due to the unusual presentation, the diversity of histological types and the complexity of treatment, taking into account the proximity of the vital structures of the head and neck to the tumour.

Due to the rarity and diversity of head and neck sarcomas, it is difficult for institutions to gain much experience. To obtain better results in the study of prognostic factors, it will be necessary to combine the experience of multiple institutions in order to add a greater number of patients and to determine with greater accuracy the factors that may influence prognosis.

\section{Conflicts of interest.}

There are no conflicts of interest.

\section{References}

1. Liuzzi J, Tirado E, and Da Cunha M, et al (2014) Angiosarcoma cutáneo cabeza y cuello Rev Venez Oncol 26(1) 45-49

2. Lindford A, Mclntyre B, and Marsh R, et al (2015) Outcomes of the treatment of head and neck sarcomas in a tertiary referral center Front Surg 219 https://doi.org/10.3389/fsurg.2015.00019 PMID: 26042220 PMCID: 4436802

3. Wanebo, H, Koness, R, and Macfarlane J, et al (1992) Head and neck sarcoma: report of the head and neck sarcoma registry Head Neck 14 1-7 https://doi.org/10.1002/hed.2880140102 PMID: 1624288

4. Colville R, Charlton F, and Kelly C, et al (2005) Multidisciplinary management of head and neck sarcomas Head Neck 27 814-824 https://doi.org/10.1002/hed.20232 PMID: 16086411

5. Gonzalez R, Bologna R, and Molina N et al (2012) Prognostic factors and treatment strategies for adult head and neck soft tissue sarcoma Int J Oral Maxillofac Surg 41 569-575 https://doi.org/10.1016/j.ijom.2012.02.002

6. Oualla K, Mellas N, and El'mrabet F, et al (2014) Adult head and neck sarcomas: rare localization with difficult therapeutic management $J$ Cancer Sci Ther 6 052-055

7. Edge S, Byrd D, and Carducci M, et al (2009) AJCC cancer staging manual 7th edition New York, United States Springer

8. Guillou L, Coindre J, and Bonichon F, et al (1997) Comparative study of the National Cancer Institute and French Federation of Cancer Centers Sarcoma Group Grading Systems in a population of $\mathbf{4 1 0}$ adult patients with soft tissue sarcoma $\mathrm{J}$ Clin Oncol 15(1) 350-362 https://doi.org/10.1200/JCO.1997.15.1.350 PMID: 8996162 
9. Salcedo-Hernández, Lino-Silva LS, and Mosqueda Taylor A, et al (2014) Soft tissue sarcomas of the head and neck Clinical and pathological evaluation of 108 cases in México J Cranio-Maxillo-Fac Surg 42 1566-1571 https://doi.org/10.1016/j.jcms.2014.01.033

10. Barker JL, Paulino AC, and Feeney S, et al (2003) Locoregional treatment for adult soft tissue sarcomas of the head and neck: an institutional review Cancer J 9 49-57 https://doi.org/10.1097/00130404-200301000-00009 PMID: 12602768

11. De Bree R, van der Valk P, and Kuik DJ, et al (2005) Prognostic factors in adult soft tissue sarcomas of the head and neck: a single centre experience Oral Oncol 42 703-709 https://doi.org/10.1016/j.oraloncology.2005.11.009

12. Le Vay J, O'Sullivan B, and Catton Ch, et al (1994) An assessment of prognostic factors in soft-tissue sarcoma of the head and neck Arch Otolaryngol Head Neck Surg 120(9) 981-986 https://doi.org/10.1001/archotol.1994.01880330061011 PMID: $\underline{8074826}$

13. Tejani M, Galloway T, and Lango M, et al (2013) Head and neck sarcomas: a comprehensive cancer center experience Cancers 5(3) 890-900 https://doi.org/10.3390/cancers5030890 PMID: 24202325 PMCID: 3795370

14. Dudhat S, Mistry R, and Varughese T, et al (2000) Prognostic factors in head and neck soft tissue sarcomas Cancer $89868-872$ PMID: 10951351 